\title{
Effect of Galactooligosaccharides on Calcium Absorption in Rats
}

\author{
Osamu CHONAN and Masaaki WATANUKI \\ Yakult Central Institute for Microbiological Research, Kunitachi 186, Japan
}

(Received June 24, 1994)

\begin{abstract}
Summary The effect of transgalactosylated oligosaccharides (TOS), which are oligosaccharides that are unhydrolyzed in the small intestine and are fermented by the intestinal bacteria, on calcium absorption was examined in male Wistar rats for 10 days. The apparent calcium absorption ratios and the apparent retention ratios were significantly higher in the rats fed TOS-containing diets ( 5 or $10 \mathrm{~g} / 100 \mathrm{~g}$ of diet). In the second experiment, the cecum was ligated in situ and calcium absorption from the cecum was observed after injecting TOS into the cecal lumen. Four hours after the injection, the calcium concentration in the cecal vein of the rats given TOS was significantly higher than that of the control. The calcium content in the liquid phase of the cecal lumen and the liquid phase weight were also increased by the injection of TOS into the cecum. Although the extent of calcium absorption from the cecum of rats fed TOS is due to overall calcium absorption is not known, under the experimental conditions used in the present study the stimulatory effect of TOS on calcium absorption may be partly associated with increased solubility of calcium and the fluid content in the intestinal lumen.
\end{abstract}

Key Words galactooligosaccharides, calcium, absorption, cecal content, fermentation

Lactose, the main carbohydrate constituent of milk products, is known to stimulate the absorption of calcium (1-3). Various other carbohydrates (3-7) and sugar alcohols $(8,9)$ have also been reported to increase calcium absorption in rats. The mechanism by which these sugars affect calcium metabolism has been studied. It is known that lactose interacts with the absorptive cells of the intestine to increase their permeability to calcium $(2)$. Goda et al. $(8,9)$ reported that maltitol enhances the rate of transepithelial calcium transport in the lower part of the small intestine by modulating the passive diffusion of calcium.

Heijnen et al. (3) reported that the calcium absorption by rats fed lactulose, which is a poorly digestible carbohydrate in the small intestine but is hydrolyzed to volatile fatty acids in the large intestine, was significantly increased and that lactulose feeding lowered the ileum luminal $\mathrm{pH}$ and raised the absolute amount of calcium in the liquid phase of the ileum. Rémésy et al. (10) also reported that 
inulin feeding increased the concentration of soluble calcium in the cecum, and the calcium absorption from the cecum was also higher in rats fed inulin. Fermentation of sugars lowered the $\mathrm{pH}$ in the intestinal lumen, and the lowered $\mathrm{pH}$ improved the solubility of the calcium (11).

Transgalactosylated oligosaccharides (TOS), which are oligosaccharides present in human milk (12), cow's milk (13), and commercial yogurt (14), are unhydrolyzed in the small intestine and then are fermented by the intestinal bacteria, especially bifidobacteria (15). It could be hypothesized that TOS lowers the $\mathrm{pH}$ in the lower part of the intestine, which enhances calcium solubility, thus stimulating its absorption. In this study, we examined the effects of TOS intake on calcium absorption by a calcium balance study. Then, to determine the effect of TOS on calcium absorption in the cecum, TOS was injected into the cecal lumen of rats and the calcium concentration of the cecal vein was measured.

\section{MATERIALS AND METHODS}

Materials. The TOS consisted of a mixture of galactosyllactoses formed from lactose by the transgalactosylation reaction catalyzed by $\beta$-D-galactosidases derived from Aspergillus oryzae and Streptococcus thermophillus. Table 1 shows the sugar composition of TOS. The main component of TOS is a trisaccharide, Gal $\beta(1-6)$ $\mathrm{Gal} \beta(1-4) \mathrm{Glc}$. The methods for preparing and purifying TOS have been described elsewhere (16).

Calcium balance study. Table 2 shows the composition of the diets. All diets used in this balance study were based on the AIN-76 formulation (17). The test diets containing 5 and 10\% TOS and 5 and 10\% lactose were formulated by adding TOS or lactose to the control diet at the expense of the sucrose component. Thirty 4-week-old male Wistar rats (Japan SLC, Inc., Shizuoka, Japan) were housed in individual aluminum metabolic cages in a temperature-controlled $\left(24 \pm 1^{\circ} \mathrm{C}\right)$ room with $60 \pm 5 \%$ humidity and a 12 -h light-dark cycle. After a 7-day adaptation period in which all rats were fed a control diet, the rats were separated into five groups of six animals having similar mean body weight. The five groups were fed one of the experimental diets and deionized water ad libitum for 10 days. Body weight and food intake were recorded every 3 rd day. For the calcium balance study, fecal and urine samples were collected from day 8 to day 10. After a 10-day feeding period, the animals were anesthetized by intraperitoneal injection of sodium pentobarbital

Table 1. Composition of galactooligosaccharides.

\begin{tabular}{lc}
\hline Galactooligosaccharides $(\%)$ & 100 \\
Monosaccharide Gal, Glc & 0 \\
Disaccharides Gal-Glc, Gal-Gal & 0 \\
Trisaccharides Gal-Gal-Glc & 55 \\
Tetrasaccharides Gal-(Gal) ${ }_{2}$-Glc & 33 \\
Penta- and hexasaccharides Gal-(Gal $)_{3}$-Glc, Gal-(Gal $)_{4}$-Glc & 12 \\
\hline
\end{tabular}


Table 2. Composition of the diets $(\mathrm{g} / 100 \mathrm{~g}$ diet $)$.

\begin{tabular}{lcccccc}
\hline & & \multicolumn{2}{c}{ TOS } & & \multicolumn{2}{c}{ Lactose } \\
\cline { 3 - 4 } \cline { 6 - 7 } & Control & $5 \%$ & $10 \%$ & & $5 \%$ & $10 \%$ \\
\hline Casein & 20 & 20 & 20 & & 20 & 20 \\
DL-Methionine & 0.3 & 0.3 & 0.3 & & 0.3 & 0.3 \\
Corn oil & 5 & 5 & 5 & & 5 & 5 \\
AIN mineral mix ${ }^{1}$ & 3.5 & 3.5 & 3.5 & & 3.5 & 3.5 \\
AIN vitamin mix ${ }^{1}$ & 1 & 1 & 1 & & 1 & 1 \\
Choline bitartrate & 0.2 & 0.2 & 0.2 & & 0.2 & 0.2 \\
Corn starch & 55 & 55 & 55 & & 55 & 55 \\
Sucrose & 10 & 5 & 0 & & 5 & 0 \\
Cellulose powder & 5 & 5 & 5 & & 5 & 5 \\
TOS & 0 & 5 & 10 & & 0 & 0 \\
Lactose & 0 & 0 & 0 & & 5 & 10 \\
\hline
\end{tabular}

${ }^{1}$ Prepared according to AIN-76 prescription (29).

( $40 \mathrm{mg} / \mathrm{kg}$ body weight) and the cecum was removed and weighed. The $\mathrm{pH}$ of the cecal lumen was measured with a glass microelectrode which was inserted into the cecum from the ileum and held in the middle of the cecum (18). The cecal wall was flushed clean with ice-cold saline, blotted on filter paper, and weighed (cecal wall weight).

Measurement of the calcium absorption from the cecum. Thirty-six 4-week-old male Wistar rats were housed in individual stainless steel cages. After they were fed a stock diet (MF, Oriental Yeast Co., Ltd., Tokyo, Japan) for 2 weeks, they were anesthetized as described above and the cecum was exposed after midline laparotomy. The cecum was tied with silk string at the sites of an entrance side and an exit side and TOS or lactose $(0.5 \mathrm{~g} / 2 \mathrm{ml}$ of saline $)$ was injected into the cecum from the entrance side with a syringe. Saline was used as a negative control. After the injection, the cut portion of the abdomen was clipped and closed (19). Two or 4 $\mathrm{h}$ later, the rats were again anesthetized by intraperitoneal injection of sodium pentobarbital and a blood sample was withdrawn from the cecal vein to determine the serum calcium concentration. Then the weight of the whole cecum and of the cecal wall, and the $\mathrm{pH}$ of the cecal lumen were determined as described above. Portions of the cecum contents were collected and then stored at $-20^{\circ} \mathrm{C}$ until they were analyzed for volatile fatty acids. The other portions of cecal contents were centrifuged at $9,000 \times g$ for $20 \mathrm{~min}$ and the resulting supernatant and the precipitation were used for calcium analysis (20).

Analysis of feces, urine, cecum, and serum. Calcium contents of feces, urine, and cecum were determined after wet ashing with nitric acid and perchloric acid, by using an atomic absorption spectrometer (Varian AA-975; Varian Tectron Pty, Ltd., Springvale, Australia). The samples were dissolved in $10 \mathrm{ml}$ of ultrapure grade $12 \mathrm{~N}$ nitric acid, then digested on a hot plate to dryness. This procedure was repeated, and then $10 \mathrm{ml}$ of a solution composed of $12 \mathrm{~N}$ nitric acid and $9 \mathrm{~N}$ 
perchloric acid $(5: 1)$ was added and the mixture was warmed to dryness. The digest was dissolved with $0.1 \mathrm{~N}$ nitric acid. The diluted solution was colorless and did not contain suspended solids. Before analysis the sample was diluted with lanthanum chloride solution (10 g/liter) (20). The absorption ratio and retention ratio of calcium were determined by the following equations:

$$
\begin{aligned}
\text { Absorption ratio }(\%)= & (\text { calcium intake }- \text { fecal calcium excretion }) \\
& \times 100 / \text { calcium intake. } \\
\text { Retention ratio } \%)= & (\text { calcium intake }- \text { fecal calcium excretion } \\
& - \text { urinary calcium excretion }) \times 100 / \text { calcium intake. }
\end{aligned}
$$

The cecal vein blood was centrifuged and the resulting serum was analyzed for total calcium. The concentration of serum calcium was determined by a colorimetric method based on the interaction of $\mathrm{Ca}^{2+}$ with $o$-cresolphthalein complexone by using a diagnostic kit (calcium C-test Wako, Wako Pure Chemical Industries, Ltd., Osaka, Japan).

Assay of volatile fatty acids. The cecal digesta $(0.3-0.5 \mathrm{~g})$ was homogenized in $1.5 \mathrm{ml}$ of water so as to make the final concentration of organic acids between 0.2 and $30 \mathrm{~mm}$. The homogenate was centrifuged at $9,000 \times \mathrm{g}$ for $10 \mathrm{~min}$ at $4{ }^{\circ} \mathrm{C}$. A mixture of $0.9 \mathrm{ml}$ of the resulting supernate and $0.1 \mathrm{ml}$ of $1.5 \mathrm{M}$ perchloric acid was allowed to stand for $2 \mathrm{~h}$ at $4{ }^{\circ} \mathrm{C}$. Then it was passed through a filter with a pore size of $0.45 \mu \mathrm{m}$ (Millipore Japan Ltd., Tokyo, Japan). The sample was analyzed for volatile fatty acid by high-performance liquid chromatography (HPLC) as previously described (18). The HPLC was performed with a TOA system (ICA-3030 TOA Electronics Co., Ltd., Tokyo, Japan) equipped with two columns (Ion Pak KC-811 Shodex, 8 mm I.D. $\times 300 \mathrm{~mm}$, Showa Denko Co., Ltd., Tokyo, Japan) and a conductometric detector (ICA-3030 TOA Electronics Co., Ltd.). The concentrations of volatile fatty acids were calculated by using external standards.

Statistical analysis. All data were analyzed by one-way analysis of variance. When significant $F$ ratios were found, individual means were compared by Tukey's test. The level of significance was considered to be $p<0.05$.

\section{RESULTS}

Growth, cecal weight, and cecal pH

The final body weight and food intake of rats fed the TOS or lactose diets were not significantly different from those in the control group (Table 3). Both whole cecal weight and cecal digesta weight were significantly elevated in rats fed the TOS diets. The cecal wall weight was also increased by feeding TOS-containing diets. Cecal $\mathrm{pH}$ was not modified by feeding the lactose-containing diets, whereas it was significantly lowered by feeding the TOS-containing diet (Table 4).

\section{Calcium balance}

Table 5 shows the apparent calcium absorption ratio and retention ratio during 
Table 3. Effect of feeding TOS- and lactose-containing diets on the body weight and food intake in rats. ${ }^{1}$

\begin{tabular}{lcccccc}
\hline & \multirow{2}{*}{ Control } & \multicolumn{2}{c}{ TOS } & & \multicolumn{2}{c}{ Lactose } \\
\cline { 3 - 4 } \cline { 5 - 6 } & & $5 \%$ & $10 \%$ & & $5 \%$ & $10 \%$ \\
\hline Initial body weight $(\mathrm{g})$ & $108 \pm 3^{\mathrm{a}}$ & $108 \pm 3^{\mathrm{a}}$ & $107 \pm 4^{\mathrm{a}}$ & & $108 \pm 6^{\mathrm{a}}$ & $109 \pm 3^{\mathrm{a}}$ \\
Final body weight $(\mathrm{g})$ & $157 \pm 15^{\mathrm{a}}$ & $161 \pm 8^{\mathrm{a}}$ & $156 \pm 6^{\mathrm{a}}$ & & $157 \pm 8^{\mathrm{a}}$ & $158 \pm 9^{\mathrm{a}}$ \\
Weight gain $(\mathrm{g})$ & $48 \pm 14^{\mathrm{a}}$ & $52 \pm 6^{\mathrm{a}}$ & $50 \pm 3^{\mathrm{a}}$ & & $50 \pm 2^{\mathrm{a}}$ & $49 \pm 10^{\mathrm{a}}$ \\
Food intake $(\mathrm{g})$ & $119 \pm 16^{\mathrm{a}}$ & $117 \pm 6^{\mathrm{a}}$ & $114 \pm 5^{\mathrm{a}}$ & & $123 \pm 7^{\mathrm{a}}$ & $117 \pm 11^{\mathrm{a}}$ \\
Feed efficiency & $0.40 \pm 0.08^{\mathrm{a}}$ & $0.44 \pm 0.03^{\mathrm{a}}$ & $0.44 \pm 0.03^{\mathrm{a}}$ & & $0.41 \pm 0.02^{\mathrm{a}}$ & $0.41 \pm 0.06^{\mathrm{a}}$ \\
\hline
\end{tabular}

${ }^{1}$ Values are means \pm standard deviations for six rats. Within the same row, means having different superscript letters differ significantly $(p<0.05)$.

Table 4. Effect of feeding TOS- and lactose-containing diets on the cecal weight and cecal luminal $\mathrm{pH}$ in rats. ${ }^{1}$

\begin{tabular}{lcccccc}
\hline & \multirow{2}{*}{ Control } & \multicolumn{2}{c}{ TOS } & & \multicolumn{2}{c}{ Lactose } \\
\cline { 3 - 4 } \cline { 5 - 6 } & & $5 \%$ & $10 \%$ & & $5 \%$ & $10 \%$ \\
\hline Whole cecal weight $(\mathrm{g})$ & $2.87 \pm 0.91^{\mathrm{a}}$ & $6.26 \pm 0.81^{\mathrm{b}}$ & $8.62 \pm 1.38^{\mathrm{b}}$ & & $2.95 \pm 0.43^{\mathrm{a}}$ & $3.19 \pm 0.38^{\mathrm{a}}$ \\
Cecal wall weight $(\mathrm{g})$ & $1.05 \pm 0.31^{\mathrm{a}, \mathrm{c}}$ & $1.33 \pm 0.11^{\mathrm{a}}$ & $1.77 \pm 0.20^{\mathrm{b}}$ & & $0.93 \pm 0.08^{\mathrm{c}}$ & $0.97 \pm 0.12^{\mathrm{c}}$ \\
Cecal digesta weight $(\mathrm{g})$ & $1.82 \pm 0.64^{\mathrm{a}}$ & $4.94 \pm 0.72^{\mathrm{b}}$ & $6.85 \pm 1.28^{\mathrm{b}}$ & & $2.03 \pm 0.38^{\mathrm{a}}$ & $2.22 \pm 0.38^{\mathrm{a}}$ \\
Cecal pH & $6.8 \pm 0.3^{\mathrm{a}}$ & $5.6 \pm 0.2^{\mathrm{b}}$ & $5.3 \pm 0.3^{\mathrm{b}}$ & & $6.5 \pm 0.2^{\mathrm{a}}$ & $6.5 \pm 0.2^{\mathrm{a}}$ \\
\hline
\end{tabular}

${ }^{1}$ Values are means \pm standard deviations for six rats. Within the same row, means having different superscript letters differ significantly $(p<0.05)$.

Table 5. Effect of feeding TOS- and lactose-containing diets on the apparent calcium absorption and retention ratio in rats. ${ }^{1}$

\begin{tabular}{lcccccc}
\hline & \multirow{2}{*}{ Control } & \multicolumn{2}{c}{ TOS } & & \multicolumn{2}{c}{ Lactose } \\
\cline { 3 - 4 } \cline { 6 - 7 } & & $5 \%$ & $10 \%$ & & $5 \%$ & $10 \%$ \\
\hline Apparent absorption (\%) & $72.0 \pm 6.6^{\mathrm{a}}$ & $81.7 \pm 4.0^{\mathrm{b}}$ & $86.3 \pm 3.6^{\mathrm{b}}$ & & $67.8 \pm 3.9^{\mathrm{a}}$ & $73.1 \pm 5.0^{\mathrm{a}}$ \\
Apparent retention (\%) & $71.9 \pm 6.6^{\mathrm{a}}$ & $81.5 \pm 3.9^{\mathrm{b}}$ & $86.1 \pm 3.6^{\mathrm{b}}$ & & $67.7 \pm 3.9^{\mathrm{a}}$ & $72.9 \pm 5.0^{\mathrm{a}}$ \\
\hline
\end{tabular}

${ }^{1}$ Values are means \pm standard deviations for six rats. Within the same row, means having different superscript letters differ significantly $(p<0.05)$.

the balance study (8-10 days). Both the apparent absorption and apparent retention ratio of calcium were significantly increased in rats fed the TOS diets, but lactose did not affect the ratios.

\section{Calcium concentration in the cecal vein}

The calcium concentration in the cecal vein was significantly elevated in rats 2 $\mathrm{h}$ after lactose was injected into their cecum. Four hours after the injection, the calcium concentration of the rats given TOS was also significantly higher than that 


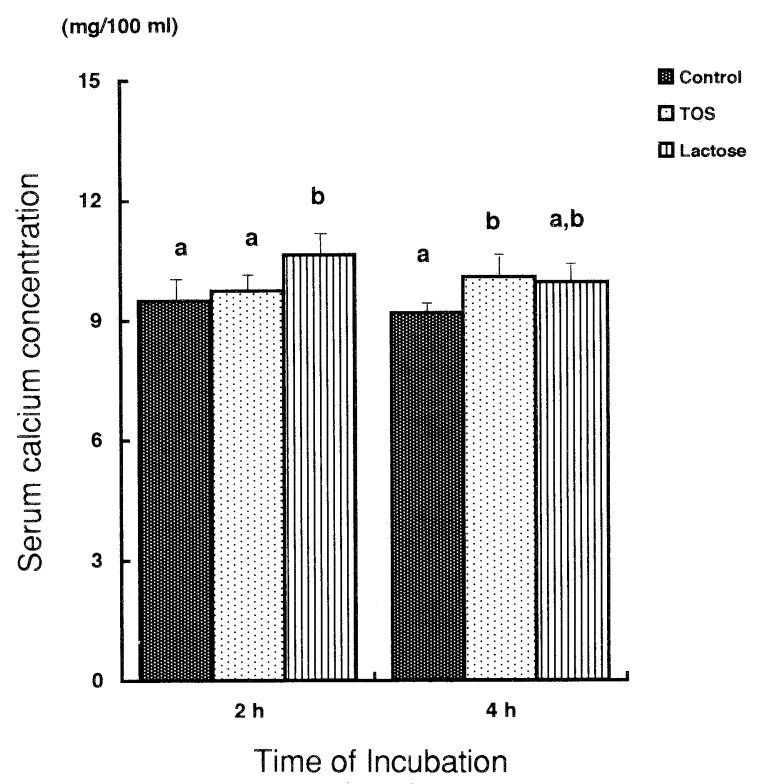

Fig. 1. Effect of TOS and lactose injection into the cecum on serum calcium concentration in the cecal vein. Columns and bars show the mean \pm standard deviation for six animals. Means having different superscript letters differ significantly at each time of measurement $(p<0.05)$.

of the control (Fig. 1).

$p H$ and volatile fatty acids in the cecal lumen

Table 6 shows the $\mathrm{pH}$ of the cecal lumen and the amount of volatile fatty acids in the cecum. The cecal $\mathrm{pH}$ was lowered when TOS or lactose was given into cecum. The total amounts of volatile fatty acids and butyric acid in the cecum contents were significantly increased by the injection of TOS or lactose into their cecum. The amount of acetic acid was significantly higher in the TOS- and lactose-injected groups than the control group after $2 \mathrm{~h}$. When lactose was present in the cecum, lactic acid was markedly increased. By the injection of lactose into the cecum, propionic acid after $2 \mathrm{~h}$ and succinic acid after $4 \mathrm{~h}$ were also significantly higher than in the control and TOS groups.

\section{Calcium in the cecal lumen}

When TOS or lactose was injected into the cecum, the liquid phase weights in the cecal lumen were significantly higher than in the control (Table 7). The calcium content in the solid phase did not differ significantly between the groups. However, the amount of calcium in the liquid phase was significantly higher when TOS or lactose was injected into the cecum. The percentage of total calcium in the liquid phase in the cecal lumen was significantly higher in the TOS- or lactose- 


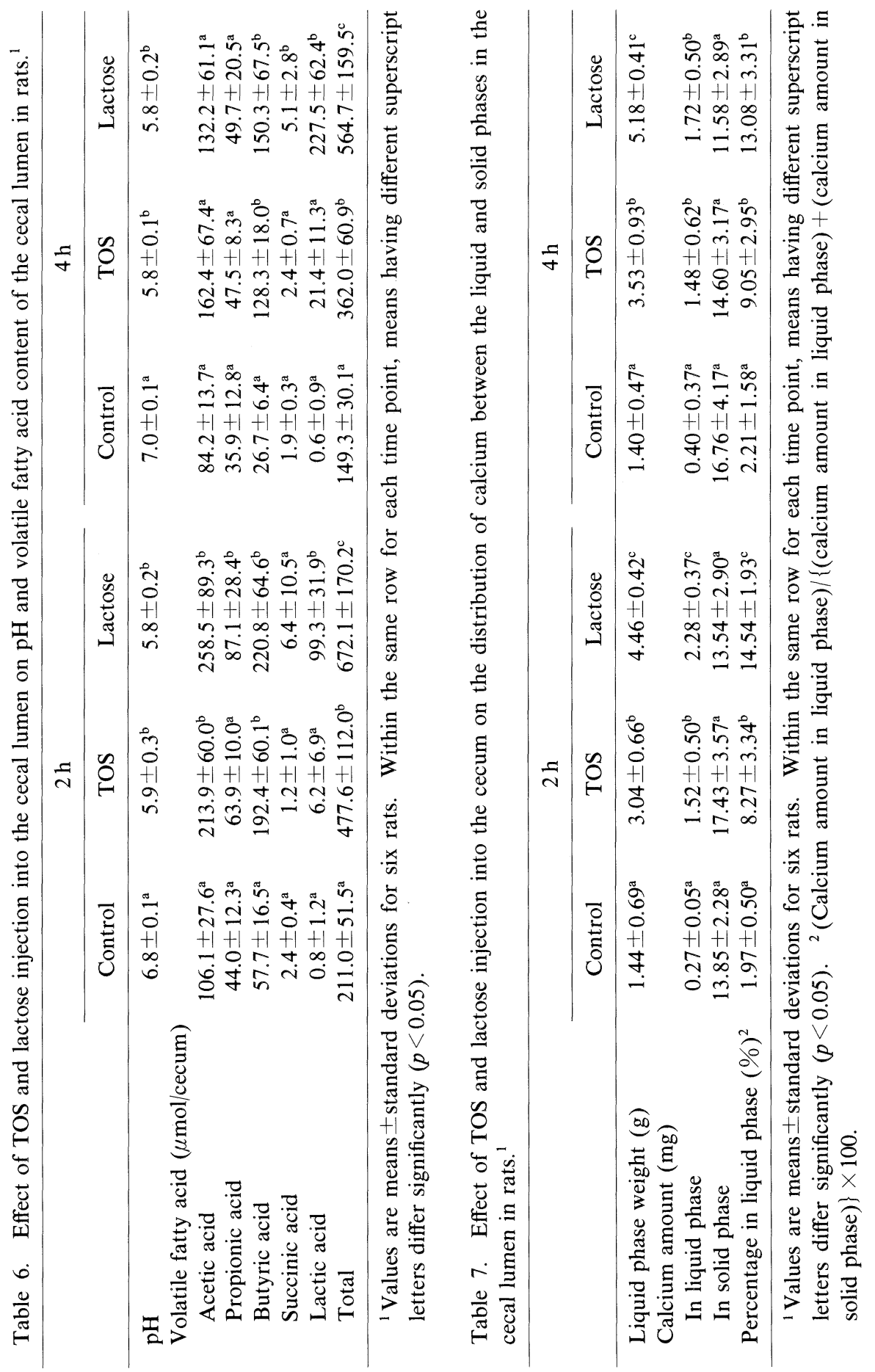

Vol. 41, No. 1, 1995 
injected group than in the control group (Table 7).

\section{DISCUSSION}

There have been many reports on the stimulatory effects of dietary lactose on calcium absorption (1-3). One hypothesis of the mechanism is that the reduced $\mathrm{pH}$ resulting from lactose fermentation in the large intestine would increase the concentration of soluble calcium (4). It is generally accepted that calcium must be in a soluble and ionized form to be absorbed in the intestine (21), and thus allow greater rates of calcium absorption.

If the stimulatory effect of lactose on intestinal calcium absorption occurs as a result of unhydrolyzed lactose in the small intestine, TOS, and other such sugars that are resistant to hydrolysis in the small intestine should have a similar effect. The stimulatory effects of dietary lactulose (3) on intestinal calcium absorption described recently could be explained in the same way. In this study, the calcium concentration in the cecal vein was significantly higher when TOS or lactose was directly injected into the cecum (Fig. 1). Our data suggest that calcium absorption from the cecum may be increased in the presence of fermentative substrates. As shown in Table 6 , the production of volatile fatty acids in the cecum of rats given TOS and lactose was markedly increased. It seems that TOS is readily fermented as well as lactose by the intestinal bacteria. Indeed the increased production of volatile fatty acids and the related $\mathrm{pH}$ reduction was associated with the increase in the calcium content in the liquid phase in the cecum of the rats given TOS (Table 7). This increase in the solubility of calcium might have elevated the amount of available calcium to be absorbed in this study $(10,11)$. Our results were in good agreement with the lactulose-induced stimulation of calcium absorption (3) which events could be explained by a similar cascade mechanism to that for our results.

On the other hand, there is evidence against the hypothesis that lactose stimulates calcium absorption in the germ-free rat $(22,23)$ and maltitol also stimulates calcium absorption in everted ileal segments (9). These findings indicate that the low $\mathrm{pH}$ in the intestine is not only related to calcium absorption.

Furthermore, Pansu et al. demonstrated that increasing the fluid content of the jejunal loop in situ stimulated calcium transport (24). The presence of osmotically active resistant sugars in the small intestine must increase the amount of fluid within the lumen to maintain isotonicity (4). As postulated by Bronner (25), this additional fluid might increase the passive absorption of calcium by increasing the permeability of the intercellular junction between enterocytes. In this study, when TOS or lactose was injected into the cecum, the liquid phase weight in the cecal lumen was significantly higher than that of the control. Such a mechanism of action for the stimulation of intestinal calcium absorption by the resistant sugars is consistent with our data.

In the present study, we focused on the cecum as a meaningful site for calcium absorption in rats fed TOS, because the cecum can absorb calcium both in vitro (26) 
and in vivo (27), and feeding lactulose is known to increase the concentration of calcium in the cecal fluid (28). Although the extent of calcium absorption from the cecum of rats fed TOS in terms of overall mineral absorption is not known, under the present experimental conditions, the stimulatory effect of TOS on calcium absorption may be partly associated with the increased solubility of calcium and the fluid content in the cecal lumen.

A part of this paper was presented orally at the 48th Meeting of the Japanese Society of Nutrition and Food Science (Fukuoka, May 13-15, 1994).

\section{REFERENCES}

1) Sato, R., Noguchi, T., and Naito, H. (1983): Effect of lactose on calcium absorption from the rat small intestine with a non-flushed ligated loop. J. Nutr. Sci. Vitaminol., 29, 365-373.

2) Armbrecht, H. J., and Wasserman, R. H. (1976): Enhancement of $\mathrm{Ca}^{++}$uptake by lactose in the rat small intestine. J. Nutr., 106, 1265-1271.

3) Heijnen, A. M. P., Brink, E. J., Lemmens, A. G., and Beynen, A. C. (1993): Ileal pH and apparent absorption of magnesium in rats fed on diets containing either lactose or lactulose. Br. J. Nutr., 70, 747-756.

4) Brommage, R., Binacua, C., Antille, S., and Carrié, A. L. (1993): Intestinal calcium absorption in rats is stimulated by dietary lactulose and other resistant sugars. J. Nutr., 123, 2186-2194.

5) Claud, A., and Edmond, S. (1986): Effects of amylomaize starch on mineral metabolism in the adult rat; Role of the microflora. J. Nutr., 116, 991-998.

6) Ohta, A., Osakabe, N., Yamada, K., Saito, Y., and Hidaka, H. (1993): Effect of fructooligosaccharides and other saccharides on $\mathrm{Ca}, \mathrm{Mg}$ and $\mathrm{P}$ absorption in rats. Nippon Eiyō Shokuryō Gakkaishi (J. Jpn. Soc. Nutr. Food Sci.), 46, 123-129.

7) Shimura, S., Saeki, Y., Ito, Y., Suzuki, K., and Goto, S. (1991): Effects of galactooligosaccharides and fructooligosaccharides on mineral utilization in rats. Nippon Eiyō Shokuryō Gakkaishi (J. Jpn. Soc. Nutr. Food Sci.), 44, 287-291.

8) Goda, T., Yamada, M., Takase, S., and Hosoya, N. (1992): Effect of maltitol intake on intestinal calcium absorption in the rat. J. Nutr. Sci. Vitaminol., 38, 277-286.

9) Goda, T., Takese, S., and Hosoya, N. (1993): Maltitol-induced increase of transepithelial transport of calcium in rat small intestine. J. Nutr. Sci. Vitaminol., 39, 589595.

10) Rémésy, C., Levrat, M. A., Gamet, L., and Demigné, C. (1993): Cecal fermentations in rats fed oligosaccharides (inulin) are modulated by dietary calcium level. Am. J. Physiol., 264, G855-G862.

11) Younes, H., Levrat, M. A., Demigné, C., and Rémésy, C. (1993): Relationship between fermentation and calcium in the cecum of rats fed digestible or resistant starch. Ann. Nutr. Metab., 37, 311-319.

12) Yamashita, K., and Kobata, A. (1974): Oligosaccharides of human milk. Isolation and characterization of a new trisaccharide, 6'-galactosyllactose. Arch. Biochem. Biophys., 161, 164-170. 
13) Saito, T., Itoh, T., and Adachi, S. (1987): Chemical structure of three neutral trisaccharides isolated in free form from bovine colostrum. Carbohydr. Res., 165, 4351.

14) Toba, T., Watanabe, A., and Adachi, S. (1981): Allolactose and 6-o- $\beta$-Dgalactopyranosyl-D-galactose in commercial yogurt. J. Dairy Sci., 65, 702-706.

15) Ito, M., Deguchi, Y., Miyamori, K., Matsumoto, H., Kikuchi, H., Matsumoto, K., Kobayashi, Y., Yajima, T., and Kan, T. (1990): Effects of administration of galactooligosaccharides on the human faecal microflora, stool weight and abdominal sensation. Microbial. Ecol. Health Dis., 3, 285-292.

16) Matsumoto, K., Kobayashi, Y., Ueyama, S., Watanabe, T., Tanaka, R., Kan, T., Kuroda, A., and Sumihara, Y. (1990): Galactooligosaccharides. in Japanese Technology Reviews, ed. by Nakakuki, T., Gordon and Breach Science Publishers, Switzerland, 90-106.

17) Ad Hoc Committee on Standards for Nutrition Studies (1980): Second report of the ad hoc Committee on Standards for Nutritional Studies. J. Nutr., 110, 1726.

18) Kikuchi, H., and Yajima, T. (1992): Correlation between water-holding capacity of different types of cellulose in vitro and gastrointestinal retention time in vivo of rats. $J$. Sci.Food. Agric., 60, 139-146.

19) Deguchi, Y., Makino, K., Iwabuchi, A., Watanuki, M., and Yamashita, T. (1993): Selection of ammonia-assimilating bifidobacteria and their effect on ammonia levels in rat caecal contents and blood. Microbial. Ecol. Health Dis., 6, 85-94.

20) Lee, Y. S., Noguchi, T., and Naito, H. (1980): Phosphopeptides and soluble calcium in the small intestine of rats given a casein diet. Br. J. Nutr., 43, 457-467.

21) Allen, L. H. (1982): Calcium bioavailability and absorption: A review. Am. J. Clin. Nutr., 35, 783-808.

22) Andrieux, C., and Sacquet, E. (1983): Effect of microflora and lactose on the absorption of calcium, phosphorus and magnesium in the hindgut of the rat. Reprod. Nutr. Dev., 23, 259-271.

23) Andrieux, C., and Sacquet, E. (1982): Microbial flora in the digestive tract and action of lactose on mineral metabolism. Reprod. Nutr. Dev., 22, 387-394.

24) Pansu, D., Chapuy, M. C., Milani, M., and Bellaton, C. (1976): Transepithelial calcium transport enhanced by xylose and glucose in the rat jejunal loop. Calcif. Tissue Res. (Suppl.), 21, 45-52.

25) Bronner, F. (1987): Intestinal calcium absorption; Mechanisms and applications. $J$. Nutr., 117, 1347-1382.

26) Nellens, H. N., and Goldsmith, R. S. (1981): Transepithelial calcium transport by rat cecum: High efficiency absorptive site. Am. J. Physiol., 240, G424-G431.

27) Ammann, P., Rizzoli, R., and Fleisch, H. (1986): Calcium absorption in rat large intestine in vivo: Availability of dietary calcium. Am. J. Physiol., 251, G14-G18.

28) Demigné, C., Levrat, M. A., and Rémésy, C. (1989): Effects of feeding fermentable carbohydrates on the cecal concentrations of minerals and their fluxes between the cecum and blood plasma in the rat. J. Nutr., 119, 1625-1630.

29) American Institute of Nutrition (1977): Report of the American Institute of Nutrition ad hoc Committee on Standards for Nutritional Studies. J. Nutr., 107, 1340-1348. 